\title{
Association of Vitamin-D levels with Sleep Disturbances
}

\section{Samina Fida, ${ }^{1}$ Saba Saif, ${ }^{2}$ Hala Mansoor, ${ }^{3}$ Javed Iqbal ${ }^{4}$}

\begin{abstract}
Objective: Vitamin-D insufficiency and sleep disturbance, both are common problems worldwide and much more common in our part of world. Two problems are associated with each other, which make the situation worse especially locally where over the counter use of even sedatives is common. Vitamin D levels and sleep quality index has been measured and association recorded in our study.

Methods: This cross-sectional analytic study was conducted in Division of Medicine, CMH Lahore from 5th April 2019 to 5th Sep 2019. A total of 106 patients presenting to medicine OPD with symptoms of Vitamin-D insufficiency\& low Vitamin-D levels were included in the study. PSQI score was calculated. Post treatment follow up Vitamin-D levels and Pittsburgh Sleep Quality Index score were recorded. Data was entered and analyzed by using spss software version 20 .

Results: Following 106 patients presenting to medical OPDs with Vitamin-D insufficiency, Mean Vitamin-D levels at first visit were \pm 20.30 with standard deviation of \pm 13.14 (CI 95\%), PSQI score in first visit was 7(SD \pm 2.66, CI 95\%) Mean Vitamin-D levels in second visit after treatment was 83.5(SD $\pm 20, C I 95 \%)$. PSQI score mean 3.1(SD 1.8, CI 95\%). Odds ratio of 3.9(95\% CI: 1.20, 12.7), Chi-Square 5.62 with p value .018 was found in first visit and 8.3 (95\% CI: 3.15, 22.0), Chi-Square 20.9 with p value $<.001$ for second visit indicating significant association of Vitamin-D deficiency with poor sleep score.

Conclusion: Sleep disturbance is associated with low Vitamin-D levels depicting as high Pittsburgh score whereas score decreases with increasing Vitamin-D levels.

Key Words: Pittsburgh Sleep Quality Index (PSQI), Vitamin D levels (Vitamin-D level), Sleep disturbances

How to Cite: Fida S, Saif S, Mansoor H, Iqbal J. Association of Vitamins D level with Sleep disturbances. Esculapio.2021;16(1):105-109.
\end{abstract}

DOI: https://doi.org/10.51273/esc20.2516423

\section{Introduction}

$\mathrm{V}$ itamin-D is one of the fat-soluble vitamins and is essential for bone health. Its discovery dates back with the discovery of rickets type bone disease in 1600-1800 as the prevalence of rickets in children increased from 40-60 \% in urban and crowded areas and later on in mid-1800 s it was found to be associated with poor sunlight exposure leading to cod liver oil replacement for treatment and finally to discovery of Vitamin-D. ${ }^{1}$

\begin{tabular}{|c|c|}
\hline 1. Samina Fida & 2. Saba Saif \\
\hline 3. Hala Mansoor & 4. Javed Iqbal \\
\hline
\end{tabular}

\section{Correspondence:}

Dr. Samina Fida, Associate Professor Medicine, Department of Medicine, CMH Lahore Medical College, Lahore, Pakistan.

E-mail:samm.doc@hotmail.com

$\begin{array}{ll}\text { Submission Date: } & 15-10-2020 \\ \text { 1st Revision Date: } & 01-12-2020 \\ \text { Acceptance Date: } & 08-12-2020\end{array}$

Vitamin-D has 2 forms i.e. D2 (ergocalciferol) mainly from plant source and D3 (cholcalciferol) obtained from diet like deep sea fish, egg yolks, liver or from synthesis in skin by Ultraviolet B light exposure to skin. Because of last two-decade insufficiency of Vitamin-D main sources are supplements and fortified foods all over the world. ${ }^{2}$ Activated Vitamin-D is formed by 1,25 hydroxylation in liver and kidney and absorbs calcium and phosphate from gut. Vitamin-D status is measured by measuring $25(\mathrm{OH}) \mathrm{D}$. Different methods of measurement were used by different investigators and till now values defined are level of $25(\mathrm{OH}) \mathrm{D}<10 \mathrm{ng} / \mathrm{ml}(25 \mathrm{nmol} / \mathrm{l})$ is considered deficiency, $11-30 \mathrm{ng} / \mathrm{ml}(26-75 \mathrm{nmol} / \mathrm{l})$ insufficient and more than $30 \mathrm{ng} / \mathrm{ml}(75 \mathrm{nmol} / 1)$ is considered sufficient. $^{3-6}$

Vitamin-D deficiency results from poor dietary intake, inadequate sunlight exposure, dark skin, obesity, malabsorption, liver and kidney disease etc. ${ }^{7,8}$ 
It has been associated with bone pains, bone diseases like rickets in kids and osteomalacia in adults. Vitamin-D insufficiency has been found to be an added risk factor with certain extra skeletal diseases like diabetes, cardiovascular disease, and malignancies and sleep disorders.

Vitamin-D supplementation is found to reduce musculoskeletal pains, 9 risk of bone disease, fractures, obstructive sleep apnea syndrome, cardiovascular mortality, diabetes, risk of cancer, infertility, autoimmunity etc. ${ }^{10-12}$ Sleep is an essential component of human life and disturbance leads to poor function of the body. ${ }^{13}$ Sleep problems are associated with Vit D deficiency so treating Vit D deficiency might help patients with sleep disturbances and decrease need of sedatives. ${ }^{14}$ Several different scales have measured sleeping hours and quality. Sleep wake activity inventory (SWAI), sleep impairment index scale (SII), sleep disorder questionnaire, Wisconson sleep Questionn-aire (WSQ), Epsworth sleepiness scale, Pittsburgh sleep quality index (PSQI) etc are the common used scales. ${ }^{15}$ PSQI is good and detailed account of Patients sleep of last 1 month. Patient can fill the Performa or Questionnaire him/herself and final score from all components can be calculated. A poor sleep score is Pittsburgh score $>5 .{ }^{16}$ This study was designed, as there is no local data on the association of Vit D insufficiency with sleep disturbances in Pakistan. So identification of insufficient Vit D cases and sleep problems associated might relieve burden of disease and bring good quality sleep with less use of sedatives by proper replacement. ${ }^{17}$

\section{Methods}

This study was conducted in Division of Medicine, CMH Lahore, from April 2019 to September 2019, after approval from Institutional Review Board (IRB), CMH Lahore (Ref No. 58/ERC/CMHLMC, dated June 9, 2020). A total of 106 patients were selected from outpatient department after calculating the sample size (95\% Confidence level, $10 \%$ margin of error and taking frequency of Vitamin D deficiency as $30 \%(14-59 \%)$. All these patients presenting in OPDs with muscle pains and lethargy and having low Vitamin-D levels were included. While those subjects who had symptoms because of some other medical illness like rheumatologic disease or uncontrolled diabetes mellitus, respiratory, psychiatric, neuropathic or myopathic problems, complicated liver, kidney or heart disease was excluded from the study. Written informed consent was taken from each patient for participation in study and confidentiality was maintained. Their demographic profiles (i.e. age, sex, occupation) were also noted using a structured questionnaire. Vitamin-D levels were recorded and grouped according to levels i.e. Deficiency $(<26$ nmole/L), Insufficiency (26-75nmole/L). ${ }^{3-6}$ Comorbid conditions and medications were recorded. All other causes which could cause sleep disturbances and any co morbid condition which was active with clinical or lab abnor-malities were excluded. Patients were asked about sleep disturbances and the ones having problem were given Pittsburgh sleep quality index score questionn-aire. Pittsburgh sleep quality index has seven components; Out of this first 4 components have questions about time to bed and actually sleeping hours whereas component no 5 assesses quality of sleep and awakening, component 6 marks need of medication for sleep, $7 \& 8$ measure effect of sleep problems on patients health and 9 is about overall quality of sleep .Each component is scored 0-3 according to severity. Total score more than 5 marks poor sleep. PSQI score was calculated from the answers about previous month sleep quality. Patients were treated with inj vitamin D3 20000 IU, PO monthly with vit D3 oral tablet 1000 units daily for 2 months followed up after two months. Vitamin d levels and PSQI score was calculated at in follow up visit. All the collected information was entered into SPSS version 20.0 and analyzed. Age, Vitamin-D levels, Pittsburgh sleep quality index score of first visit and 2 months follow up visit were presented as mean and \pm standard deviation. Frequency tables were made for gender, co morbid conditions, sleep disturbances, medications; Vitamin d levels were correlated with sleep disturbances both for first visit and 2 months follow up visit using Odds ratio and Chi-Square. Confounders like co morbid conditions, age and gender were analyzed by using Logistic regression analysis and adjusted odds ratio was calculated.

Pvalue $<0.05$ was considered significant.

\section{Results}

A total of 106 patients were enrolled according to inclusion criteria having symptoms and low vitamin D levels. Out of these $29(27.7 \%)$ patients were males whereas 77(72.6\%) were females. From 106 indivi- 
duals, 27 patients (25.5\%) were of age group 13-30, $77(72.6 \%)$ were of age group 31-60 and 2 (1.9\%) patients were of age 61-90. Majority of patients $(67.9 \%)$ had no co-morbid condition or medical illness

In first observation Vitamin-D deficiency (level less than $26 \mathrm{nmole} / \mathrm{L}$ was seen in 90 (84.9\%), 16 patients (15.1\%) had level between 26-75 (Vitamin-D insufficiency). Sleep recording of previous month showed that 18 patients (16\%) had Pittsburgh sleep quality index score of 1-5 (mild to moderate problem) and $88(83 \%)$ had Pittsburgh sleep quality index score of $>5$ (poor sleep, severe problem). Use of sedatives was seen in 34 whereas 51 were not using any medication. In co morbid record, 6 patients $(5.7 \%)$ had Diabetes mellitus, 11(10.4\%) had hypertension, 4(3.8\% patients had thyroid disorder 1 patient was asthmatic of mild intermittent type, 10 patients had some rheumatologic disorders out of which 5 had osteoarthritis, 3 Fibro-myalgia, 1 of gout and 1 of rheumatoid arthritis in remission with DMARDS, Two patients had other medical illnesses including heart disease and liver disease in each and none had neuropathy. All of these patients were stable and in remission as account of their disease control with no active clinical or lab abnormality thus ruling out possibility of sleep distur-bances by these problems All 6 patients with associa-ted diabetes mellitus had Vitamin-D level $<26$ and all-11 patients having hypertension also showed Vit D deficiency with level $<26 \mathrm{nmole} / \mathrm{L}$

Mean a Vitamin-D level at first visit was \pm 20.30 with standard deviation of \pm 13.14 (CI 95\%), Pittuburgh scale in first visit was 7(SD \pm 2.66 , CI 95\%. (Table-I). There was negative correlation between vitamin $\mathrm{D}$ levels with Pittsburgh sleep scale of $-0.15(p<0.05)$ (Table-I). In second observation after treatment with Vitamin-D 320000 IU monthly PO for two months Vitamin-D deficiency (level less than $26 \mathrm{nmole} / \mathrm{L}$ was seen in $38(35 \%), 68$ patients $(65 \%)$ had level between 26-75 (Vitamin-D insufficiency).
Sleep recording of previous month showed that 78 patients (73\%) had Pittsburgh sleep quality index score of 1-5 (mild to moderate problem) and 28(26\%) had Pittsburgh sleep quality index score of $>5$ (poor sleep, severe problem). Use of sedatives was seen in 34 whereas 51 were not using any medication. Significant association was found between sleep disturbance with Odds ratio of 3.9 (95\% CI: 1.20, 12.7), Chi square 5.62 and $p$ value .018 . Adjusted odds ratio was 3.85 with $\mathrm{p}$ value .02 in logistic regression analysis with confounders. (Table 2)

Mean Vitamin-D level in second visit was 83.5( $\mathrm{SD} \pm$ 20, CI $95 \%$ ). PSQI score mean 3.1(SD \pm 1.8 , CI 95 $\%$,). Odds ratio of $8.33(95 \% \mathrm{CI}: 3.14,22.0)$ with ChiSquare $20.9, \mathrm{p}$ value .000 was found in second visit indicating significant association of vitamin D deficiency with poor sleep score. Adjusted Odds ratio was 8.48 with $p$ value $.000(<.001)($ Table 3$)$

\section{Discussion}

This is study from a tertiary care hospital establishing sleep disturbances in Vitamin-D deficient patients. We found that in absence of other causes of sleep disturbances Vitamin-D patients had decreased sleep hours and poor sleep quality with odds ratio of 3.9 in first visit and 8.3 in second visit. Sleep is very important for wellbeing of any person and factors affecting poor sleep need proper evaluation and treatment accordingly. Vitamin-D deficiency is common all over the world and more in our region because of dark skin and inadequate fortification of food like seen in developed world. Moreover, poverty keeps people in circle of finding basic food items and deprives them

Table 1: Demographic Details and Disease Characteristics

\begin{tabular}{lcc}
\hline & Mean & $\begin{array}{c}\text { Standard } \\
\text { Deviation }\end{array}$ \\
\hline Age & 41.11 & 15.04 \\
Vitamin-D level first visit & 20.30 & 13.14 \\
Pittsburgh sleep quality index first visit & 6.62 & 2.66 \\
Vitamin-D level 2 $^{\text {nd }}$ visit & 83.51 & 20.74 \\
Pittsburgh sleep quality index 2 $2^{\text {nd }}$ visit & 3.11 & 1.90 \\
\hline
\end{tabular}

Table 2: Risk of Sleep Disturbances in Vitamin-D Deficiency First Visit.

\begin{tabular}{|c|c|c|c|c|c|c|c|c|}
\hline & & \multicolumn{2}{|c|}{ PSQI score } & \multirow{2}{*}{ Total } & \multirow{2}{*}{ OR } & \multirow{2}{*}{ Adjusted OR } & \multirow{2}{*}{ Chi-Square } & \multirow{2}{*}{ P-value } \\
\hline & & $>5$ & $<5$ & & & & & \\
\hline \multirow{3}{*}{$\begin{array}{l}\text { Vitamin-D } \\
\text { Deficiency }\end{array}$} & $<25$ & 78 & 12 & 90 & \multirow{4}{*}{3.9} & \multirow{4}{*}{3.9} & \multirow{4}{*}{5.62} & \multirow{4}{*}{.018} \\
\hline & $26-75$ & 10 & 06 & 16 & & & & \\
\hline & & 90 & 16 & 106 & & & & \\
\hline Total & & $100.0 \%$ & $100.0 \%$ & $100.0 \%$ & & & & \\
\hline
\end{tabular}


Table 3: Risk of Sleep Disturbances in Vitamin-D Deficiency 2nd Visit.

\begin{tabular}{|c|c|c|c|c|c|c|c|c|}
\hline & & \multicolumn{2}{|c|}{ PSQI score } & \multirow{2}{*}{ Total } & \multirow{2}{*}{ OR } & \multirow{2}{*}{ Adjusted OR } & \multirow{2}{*}{ Chi-Square } & \multirow{2}{*}{ P-value } \\
\hline & & $>5$ & $<5$ & & & & & \\
\hline \multirow{2}{*}{$\begin{array}{l}\text { Vitamin-D } \\
\text { Deficiency }\end{array}$} & $<75$ & 20 & 18 & 38 & \multirow{3}{*}{8.33} & \multirow{3}{*}{8.48} & \multirow{3}{*}{20.9} & \multirow{3}{*}{.000} \\
\hline & & 28 & 78 & 106 & & & & \\
\hline Total & & $100.0 \%$ & $100.0 \%$ & $100.0 \%$ & & & & \\
\hline
\end{tabular}

with so-called luxury of nutrient rich food like fish. Vitamin D deficiency is affecting Pakistani population irrespective of age gender or area and cases recorded are only tip of the iceburg. ${ }^{18,19}$ Vitamin-D deficiency has been proven to be associated with many diseases and sleep disturbances Sleep deprivation or disturbance is also found to be associated with increased risk of certain diseases and all-cause mortality. ${ }^{20}$ Vitamin-D deficiency has been found to be related with severity of liver disease in local population. ${ }^{21}$ Considering that, Vitamin-D replacement can reduce risk of diseases, severity of certain diseases, can decrease analgesic and sedatives use and can improve sleep quality. ${ }^{22,23}$

Cheng et al. found that severe Vitamin-D deficiency is associated with sleep disturbances odds ratio calculated was 4.14(CI 95\% 2.01,8.52) p-value $<0.001$ ) in pregnant females in Singapore. ${ }^{17}$ Eckini et al. conducted a study on pediatric population to know link between Vitamin-D and vitamin B12 deficiency with sleep disturbances and an association was found OR $1.93(95 \% \mathrm{CI}, 0.65-5.76, \mathrm{P}<0.001) .{ }^{24}$ similar link was found by Jung YS et al where an OR of 1.36 was found $(95 \% \mathrm{CI}, 1.01,1.83)$ in fixed day field workers in the electronics manufacturing industry in Korea. ${ }^{25}$ Piovezan RD found an association of obstructive sleep apnea as well as short sleep duration with Vitamin-D deficiency with OR 2.15(CI 95\%, 1.21, 3.81). In our study we used Pittsburgh sleep quality index which measures sleep duration, quality of sleep and need for medications. It measures record of previous month sleep and is better marker of any kind of sleep disturbances. A negative correlation was found in our study of Vitamin-D levels with sleep disturbances. Higher Vitamin-D levels showed lower PSQI score and lower Vitamin-D levels showed higher PSQI scores. There are no local studies to find this asso-ciation although two studies as mentioned above have been reported from Korea and Singapore. The prob-lem is worst in developing countries as developed world has almost overcome the problem by fortifica-tion of food, healthy diet facilities, education and good health care services.

As prevalence of Vitamin-D deficiency and its association with bone diseases, sub-fertility, liver disease, cardiovascular disease, tuberculosis etc. has been studied in Pakistani population ${ }^{18,21}$, Our study will add its association with sleep disturbances in literature which in turn might help patients by finding cause of their sleep disturbance and treatment by vitamin D replacement so that patient will get rid of sedatives use and addiction

\section{Conclusion}

Higher frequency of sleep disturbances is observed in patients with vitamin D deficiency. Vitamin-D deficiency is found at any age younger to older individuals but seen more common in females having more sleep disturbances getting worse during pregnancies.

\section{Conflict of Interest: None}

\section{References}

1. Horlick MF, Biancuzzo RM, Chen TC, Klein EK, Young A, Bibuld D, et al. Vitamin D2 is as effective as vitamin D3 in maintaining circulationg concentration of 25-hydoxyvitamin D. J Clin Endocrinol Metab. 2008; 93(3):677-681. doi: 10.1210/jc.2007-2308

2. Kennel KA, Drake MT, Hurley DL. Vitamin D deficiency in adults: when to test and how to treat. Mayo Clin Proc. 2010;85(8):752-757. doi: 10.4065/ mcp. 2010.0138

3. Chapuy MC, Preziosi P, Maamer M, Arnaud S, Galan P, Hercberg S, et al. Prevalence of vitamin D insufficiency in adults' normal population. Osteoprosis Int.1997;7(5):439-443.doi:10.1007/s001980050030

4. Thacher TD, Clarke BL. Mayo Clin Proc. 2011; 86(1): 50-60. doi:10.4065/mcp.2010.0567

5. Heaney RP. Functional indices of vitamin D status and ramifications of vitamin D deficiency. Am J Clin Nutr. 2004;80(Suppl 6):1706S-1709S. doi: 10.1093/ ajcn/ 80.6.1706S

6. Hollis BW, Wagner CL, Drezner MK, Binkley NC. Circulating vitamin D3 and 25 hydroxyvitamin D in humans:an important tool to define adequate nutritional vitamin D status. J Steroid Biochem Mol Biol. 
2007;103(3-5):631-634. doi: 10.1016/j. jsbmb. 2006. 12.066

7. Hagenau T, Vest R, Gissel TN, Poulsen CS, Erlandsen $\mathrm{M}$, Mosekilde L, et al. Global vitamin D levels in relation to age, gender, skin pigmentation and latitude: an ecologic meta-regression analysis. Osteoporosis Int. 2009;20:133-140. doi: 10.1007/s00198008-0626-y

8. Gonzalez-Gross M, Valtuena J, Breidenassel C, Moreno LA, Ferrari M, Kersting M, et al. Vitamin D status among adolescents in Europe: the Healthy Lifestyle in Europe by Nutrition in Adolescence study. Br J Nutr. 2012;107(5):755-764. doi: 10.1017/ S0007114511003527

9. Le Goaziou MF, Kellou N, Flori M, Perdrix C, Dupraz C, Boldier E, et al. Vitamin D supplementation for diffuse musculoskeletal pain: results before - and-after study. Eur J Gen Pract. 2014;20:3-9. doi: 10.3109/13814788.2013.825769

10. Mete T, Yalcin Y, Berker D, Kiftci B, Guven SF, Topaloglu O, et al. Obstructive sleep apnea syndrome and its association with vitamin d deficiency. J Endocrinol Invest. 2013;36:681-685. doi: 10.3275/ 8923

11. Rorie A, Goldner WS, Lyden E, Poole JA. Beneficial role for supplemental vitamin D3 treatment in chronic urticaria: a randomized study. Ann Allergy Asthma Immunol. 2014;112(4):376-382. doi: 10. 1016/j.anai.2014.01.010

12. Mozos I, Marginean O. Links between vitamin D deficiency and cardiovascular diseases. BioMed Res Int. 2015;109-275. doi: 10.1155/2015/109275

13. Hirshkowitz M, Whiton K, Albert SM, Alessi C, Bruni O, Don Carlos L, et al. National sleep foundation's sleep time duration recommendations: Methodology and Result summary. Sleep Health. 2015;1:40-43. doi: 10.1016/j.sleh.2014.12.010

14. Bhaskar S, Hemavathy D, Parasad S. Prevalence of chronic insomnia in adult patients and its correlation with medical comorbidities. J Fam Med Prim Care. 2016;5:780-784. doi: 10.4103/2249-4863.201153

15. Stang A. Critical evaluation of the Newcastle-Ottawa scale for the assessment of the quality of nonrandomized studies in meta-analyses. Eur J Epidemiol. 2010;25:603-605. doi: 10.1007/s10654-010-9491-z

16. Buysse DJ, Monk TH, Berman SR, Kupfer DJ. The pittsburgh sleep quality index: A new instrument for psychiatric practice and research. Psychiatry Res.
1989;28:193-213. doi: 10.1016/0165-1781(89) 90047-4

17. Cheng TS, Loy SL, Cheung YB, Cai S, Colega MT, Godfrey KM, et al. Plasma vitamin d deficiency is associated with poor sleep quality and night-time eating at mid-pregnancy in Singapore. Nutrients. 2017;9:340. doi: 10.3390/nu9040340

18. Jadoon SA, Ahmed A, Alam MA. Vitamin-D deficiency in Pakistan: tip of iceberg. J Ayub Med Coll Abbottabad. 2018;30(1):78-80.

19. Riaz H, Finlayson AE, Bashir S, Hussain S, Mahmood S, Malik F, et al. Prevalence of Vitamin-D deficiency in Pakistan and implications for the future. Expert Rev Clin Phar. 2016;9(2):329-338. doi: 10. 1586/17512433.2016.1122519

20. Aurora RN, Kim JS, Crainiceanu C, O 'Hearn D, Punjabi NM. Habitual sleep duration and all-cause mortality in a general community sample. Sleep. 2016;39:1903. doi: 10.5665/sleep.6212

21. Falak S, Aftab L, Saeed M, Islam A. Prevalence of Vitamin-D deficiency is related to severity of liver damage in Hepatitis-C patients. Pak J Med Sci. 2020; 36(3):445-450. doi: doi: 10.12669/pjms.36.3.1490

22. Shahi MM, Husseini SA, Helli B,H aghighyzade MH, Abofathi M.The effect of vitamin d supplement on quality of sleep in adult people with sleep disorders. Tehran Univ Med J. 2017;75:443-448. doi: 10. 1080/1028415X.2017.1317395

23. Hauang W, Shah S, Long Q, Crankshaw AK, Tanpricha V. Improvement of pain, sleep, and quality of life in chronic pain patients with vitamin d supplementation. Clin J Pain. 2013;29:341-347. doi: 10.1097/AJP.0b013e318255655d

24. Ekinci RMK, Balci S, Serbes M, Dogruel D, Altintas DU, Yilmaz M, et al. Decreased serum vitamin b12 and vitamin D levels affect sleep quality in children with familial Mediterranean fever. Rheumatol Int. 2018;38:83-87. doi: 10.1007/s00296-017-3883-2

25. Jung YS, Chae CH, Kim YO, Son JS, Kim CW, Park $\mathrm{HO}$, et al. The relationship between serum vitamin D levels and sleep quality in fixed day indoor field workers in the electronics manufacturing industry in Korea. Ann Occup Environ Med. 2017;29:25. doi: 10.1186/s40557-017-0187-7

\section{Author's Contribution}

FS: Design manuscript, statistical analysis

SS: Data collection

MH, IJ: Statistical analysis 